\title{
Some Recommendations for Integrating Literature into EFL/ESL Classrooms
}

\author{
Mohammad Khatib \\ Allameh Tabataba'i University, Tehran, Iran \\ E-mail: mkhatib27@yahoo.com \\ Saeed Nourzadeh (Corresponding author) \\ Allameh Tabataba'i University, Tehran, Iran \\ E-mail: saeednourzadeh@yahoo.com
}

Received: May 23, 2011 Accepted: June 23, 2011 doi:10.5539/ijel.v1n2p258

\begin{abstract}
Many EFL/ESL learners find English language classrooms boring, partly because of the fact that learners are engaged in those activities they consider unrelated to the requirements of out-of-class communication in the L2. One solution offered to this problem is to introduce literature and literary texts into language classrooms. Many researchers support the proposal that literature needs to be incorporated into language teaching curricula, both for children and adults. However, researchers and ELT practitioners do not agree as to what are the most effective procedures for integrating literature into language classrooms. It is the purpose of the present paper to offer some recommendations that would help language teachers maximize the efficacy of their literary materials. Ten recommendations will be proposed with a specific focus on short stories and novels along with the rationales as to why it is thought that the recommendations would be helpful for literature-based language classrooms.
\end{abstract}

Keywords: Literature, Literary texts, Short stories, Novels, Literature-based language classrooms, EFL/ESL learners

\section{Introduction}

Traditionally, literature had a central role in language classrooms generally as a result of the dominance of grammar-translation approaches to second language teaching (Howatt, 1984). However, there were several problems with the utilization of literary texts in traditional language classrooms. First, in such traditional classrooms, the use of literature meant tiresome memorization of word lists extracted from literary texts and translation of literary classics. What was scarified in between was the beauty of literature for which a literary text is created and admired. Second, most of the teachers in traditional classrooms were graduates of English literature who tried to teach literature the same way they were taught. This involved critical, rhetorical, and stylistic analyses of literary texts; activities which did not match the communicative needs of language learners. Finally, literature was taught in a vacuum as a result of an ontological perspective which tried to establish "an essential, timeless property of what literature or literary language is" (Carter, 2007, p. 5). Therefore, no references were made to the particular spatiotemporal circumstances in which a literary text had been created and no comparisons were made between the learners' cultural traditions and those of the text.

Because of the above-mentioned problems language teachers began to think of literature as an unhelpful means for the attainment of teaching and learning goals. However, in recent years language teachers have recognized the potentiality that literary texts (especially short stories and novels) can have for the development of different aspects of a second language. It is argued that literature promotes learners' L2 vocabulary knowledge (Frantzen, 2002; Tayebipour, 2009), grammatical knowledge (Tayebipour, 2009), knowledge of L2 lexical phrases and fixed expressions (MacKenzie, 2000), language awareness (Chan, 1999), and sociolinguistic and pragmatic competences (McKay 2001).

In the present paper, ten recommendations would be proposed that are thought to help language teachers maximize the efficacy of their literary materials for the attainment of L2 teaching objectives. The recommendations are based upon the current thinking about the role of literature in language classrooms and also 
based upon our own experiences in exploiting literature and literary texts in our own language classrooms. Rationales will be given as to why it is assumed that the recommendations would be helpful for literature-based language classrooms.

\section{The Ten Recommendations for Integrating Literature into Language Classroom}

\subsection{Recommendation One: The teacher should work for learners' personal involvement with literary texts}

Although literary texts are spatiotemporally contextualized into particular societies and cultures, they usually deal with themes and topics that are universal:

No known language is without literature (oral or written). The themes literature deals with are common to all cultures, though the treatment of them may be different - Death, Love, Separation, Belief, Nature ... the list is familiar. And even the genres, conventions, and devices employed by literature are common across cultures (though of course there is no one-to-one correspondence). (Maley, 1989, p. 12).

The universality of literature implies that literary texts written in one particular language are emotionally, intellectually, and pedagogically accessible to speakers from other languages as well. However, what is of importance is that learners should have the opportunity to draw on their personal experiences to understand and interpret literary texts. Thus, language teachers are recommended to allow learners to relate what they read in literary texts to what they have experienced during their lives (Floris, 2004). Such personal involvement with literary texts increase learners' pleasure of reading literary texts and helps them socialize into particular cultures (ibid.). The significant role of literature in human development and socialization has also been stressed by McGinley et al. (1997) with respect to stories, contending that "stories can be a means of personal and social exploration and reflection - an imaginative vehicle for questioning, shaping, responding, and participating in the world" (p. 43).

Also, learners' personal involvement with literary texts has a motivational function since, if literary texts learners are required to read has no relevance to their experiences and needs, they will not be interested to read them (Floris, 2004). Therefore, teachers are highly advised to select those literary texts that are relevant to learners' lives and expectations and that appeal to their interests.

\subsection{Recommendation Two: The inclusion of literary texts does not mean the exclusion of other text types}

The question of whether or not language teachers should use literary texts in their classrooms is not equivalent to the "question of either literature or prose" (McKay, 1982, p. 530). Further, it is not the case that we can simply distinguish between literary texts and other text types; that is, they can be seen more accurately as comprising a continuum (Gajdusek, 1988, p. 228) rather than a dichotomy. Our belief is that literary texts and other text types are best exploited in complementary fashion than in isolation.

A related second issue concerns the relative extent to which literary texts and expository prose should be used in language classrooms. No catch-all prescription can be given since determining to what extent each type of text (i.e., literary vs. expository) should be employed depends upon a set of local classroom factors including the accessibility of each text type, language teaching and learning purposes, learners' L2 proficiency levels, their language and content needs, etc.

2.3 Recommendation Three: In language classrooms, literature serves as a resource for language learning, not as an end in itself

Since the ultimate objective of language teaching curricula is to develop learners' L2 proficiency so that they can cope with the requirements of out-of-class communication in the L2, language teachers should see literature as a resource for the attainment of that ultimate objective and not as an end in itself. As Edmondson (1997) contends, for language teachers, what is "at issue is the value of literature for language learning, and not the value of literature per se" (p. 46). Of course we do not wish to imply that literature cannot and should not be studied as a subject matter on its own. Students who are majoring in, for instance, English classical literature would for sure benefit from critical and stylistic analyses of literary texts. However, we as language teachers are more concerned with the mediatory role of literature (i.e., using it as a resource for language learning and teaching) than its role as subject matter content.

\subsection{Recommendation Four: Learners should have the chance to use literary language in creative ways}

Language use is not stimulus-dependent in that language users choose what they say and how they say it. Further, human beings are creative language users who are able to cope with new communication challenges they encounter in their daily lives. This is true of both first language and second language and in fact creativity is a 
characteristic feature of human language. Therefore, the ultimate goal of any language teaching curriculum should be to prepare learners to be able to produce and comprehend language in creative ways. It would be desirable if this language creativity could be practiced and fostered in literature-based language classrooms as well.

To date, little has been written as to how learners' literary creativity can be promoted. One example is Preston (1982) who offers poetry writing "as a means of directly and actively involving foreign students in communicative, creative uses of English" (p. 489, emphasis is added). In poetry writing, learners are asked to create their own original poems based upon ideas given to them. This can be done both individually and in collaboration. In Preston's (1982) study, the learners first were asked to write original poems on two ideas (describing a person and describing a place). Then, the learners were placed into groups and each group was required to "select comparisons from each other's poems and put together a single class poem based on a collection of their many images" (p. 494).

Another useful technique to provoke learners' literary creativity is to ask them read a short story or a novel and then to rewrite it, relating it to their own experiences or relying on their imagination to expand it. Such practices would generate a sense of excitement in learners and would make them use their imaginative powers in ways which are helpful for the development of their communicative skills.

\subsection{Recommendation Five: Teachers should consider the accessibility of literary texts for their language classrooms}

When using literature as a resource for teaching a second language, language teachers should take into account the accessibility of literary texts they are going to employ in their language classrooms. As used here, the term accessibility refers to two things. First, it refers to the requirement that language learners should be provided with a wide range of literary texts from which they can choose based upon their needs and interests. Learners' access to a large number of books has a positive motivational function because research has shown individuals are motivated to read more if they have enough access to appropriate books (Krashen, 1998; Neuman \& Celano, 2001).

Second, it refers to a set of factors that would facilitate the understanding and interpretation of literary texts and therefore need to be taken into consideration when selecting literary-texts for EFL/ESL classrooms. As used in this latter sense, Vardell, Hadaway, \& Young (2006) emphasize that literary texts for language classrooms (including fictions, non-fictions and poems) need to be selected according to the following criteria:

- Content accessibility: Is the story or topic familiar or helpful?

- Language accessibility: Is the language of the book simple and direct?

- Visual accessibility: Are there abundant illustrations?

- Genre accessibility: Are there a variety of genres available?

- Cultural accessibility: Is the book culturally connected to the lives of students?

- Accuracy and organization accessibility: Is the book accurate and well-organized?

It is important to realize that the two aforementioned senses of the term accessibility are functionally related. The first sense requires that learners be provided with a large collection of literary texts; however, the range and type of the collection would be constrained by the selection criteria listed above.

\subsection{Recommendation Six: The four language skills (listening, speaking, reading, and writing) should be} integrated

Current theories of second language acquisition stress that the teaching of the four language skills (i.e., listening, speaking, reading, and writing) be integrated. As Hinkel (2006) states, "[i]n an age of globalization, pragmatic objectives of language learning place an increased value on integrated and dynamic multiskill instructional models with a focus on meaningful communication and the development of learners' communicative competence" (p. 113).

The same holds true of the utilization of literature in language classrooms and there is an ever-growing contention that literature can encourage and facilitate the integration of the four language skills within classrooms (Ghosn, 2002; McKay, 2001). For instance, short stories novels can stimulate interesting topics for classroom and group discussions or learners can rewrite them, using their personal experiences or relying on their imaginative powers (see Recommendation Four above). Another technique for integrating different 
language skills within literature-based language classrooms is to have learners listen to a tape-recorded short story and write a summary of it.

\subsection{Recommendation Seven: Nativization of literary texts should be employed whenever it is helpful}

It is well-accepted in the EFL/ESL literature that full comprehension of a text depends to a large extent upon the background knowledge that the reader brings to the text (Bugel \& Buunk, 1996; Nassaji, 2002). The role of background knowledge is also important with respect to short stories and novels where the interpretation of meaning nuances is a function of the extent to which the reader is familiar with the referents of the cultural cues provided by the text. This hypothesis has been supported by Steffensen et al. (1979) who found that second language stories will be more comprehensible to learners if they are consistent with their first language cultural patterns. As is common in literary analysis and criticism, cultural cues within a literary text are subsumed under the four features of setting (when and where the story is happening), point of view (who is narrating the story), character (who the story is about), and action (what happens in the story). The problem is that literary texts written in a particular language may pose interpretability problems to language learners because their authors "take for granted the cultural assumptions of native speakers of that language" (Alptekin, 2006, p. 496).

One solution offered to this problem is text nativization. As Alptekin (2006) defines it, nativization refers to the process of "the sociological, semantic, and pragmatic adaptation of the textual and contextual cues of the original story into the language learner's own culture, while keeping its linguistic and rhetorical content essentially intact" (p. 499). In Alptekin's (2006) study, an original English story was nativized into Turkish by replacing the characters, events, places, customs, and social relations in the story with their Turkish parallels (e.g., replacing Istanbul for New York, Gulhane Park for Coney Island, mosque for church, sea for ocean, piano player for organist, etc.). The results of the study showed that nativization of the L2 text helped the learners utilize their inferencing skills more efficiently during the process of reading comprehension (p. 503).

However, something seems paradoxical here. How learners should be encouraged to engage in experiencing the feelings of a literary text the contextual settings of which have been nativized? In other words, there seems to exist a take-off between the process of nativizing a literary text and the extent to which learners are expected to understand the text as it is intended by the author. Anyway, nativizing literary texts appears essential especially when we are teaching English in contexts where it is not spoken as a native language (i.e., EFL contexts) because learners cannot find referents for the sociocultural cues of literary texts in their surrounding environment.

\subsection{Recommendation Eight: The teacher should provide scaffolded assistance with literary texts}

Closely related to the process of nativization described above is the need that learners should be assisted with the understanding and interpretation of literary texts they want and are required to read through the process of scaffolding. As used in this paper, scaffolding refers to the situation where learners "are challenged by a task beyond their current level of competence, but provided with task-specific support by a more competent adult or peer" (Murray \& McPherson, 2006, p. 139). One good example of how teachers can employ the concept of scaffolding to improve their learners' understanding of and engagement with literary texts is Doiron, (2009). Doiron proposes a five-unit lesson plan the purpose of which is to motivate learners to read and help them understand F. Scott Fitzgerald's The Great Gatsby. The five lesson units include the following procedures; (1) setting the scene, (2) character exploration, (3) visualization, (4) understanding the climax, and (5) having learners present their character descriptions.

Similarly, Khatib et al. (2011) propose a task-based approach to the teaching of literature within language classrooms where teachers are suggested to employ a teaching scheme consisting of three phases of pre-task, during-task, and post-task. Of particular interest to the present section is the pre-task phase the purpose of which is to activate learners' background knowledge structures and expose them to authentic materials related to the literary text to be read. Khatib et al. (2011) propose the following lesson scheme for the pre-task phase:

\section{Schema Building}

\section{A. Brainstorming}

a. Contextualization of the task (through pictures, realia, questions, and answers)

b. Illustration of the context

c. Introduction of some of the key vocabulary items (through matching, predicting, and guessing)

B. Group scaffolding

C. Performing a similar task chorally 


\section{Authentic Listening Exposure}
A. Exposure to pertinent songs
B. Listening to the relevant story

As it is evident from the above scheme, the purpose of the pre-task phase is to prepare learners to go about the process of reading a literary text. Whatever technique or lesson scheme is used to teach literature, it is important to keep in mind that literary materials should be presented to learners in a way that challenges them to go beyond their current proficiency in the L2 and, at the same time, provide them with scaffolded assistance in understanding and interpreting the text.

\subsection{Recommendation Nine: The teacher should encourage and facilitate group discussions}

The advent of L2 communicative competence frameworks and their practical successors (i.e., Communicative Language Teaching, Task-Based Language Instruction, etc) during 1970s to 1990s made teachers aware of the potentials group communicative activities would have for the development of L2 communicative skills. Literature is seen as one way to provide opportunities for such activities (Hişmanoğlu, 2005). According to Hişmanoğlu (2005), most of what a literary text is intended to communicate to its readers is not explicitly stated by explicit linguistic forms but rather should be inferred from the text. This fact should be welcome by language teachers since they would be able to engage learners in group communicative activities in which learners can discuss their own interpretations of a literary text and give feedback to those of their classmates. In groups, learners can also discuss their own life experiences which are related to the theme of the literary texts in hand.

\subsection{Recommendation Ten: Learners should be protected against cultural imperialism}

It goes with saying that literature provides good opportunities for ESL/EFL learners to become familiar with the culture of a second language. On the other hand, the understanding of L2 literary texts depends, to a large amount, upon learners' familiarity with the cultural concepts included in the text. However, sometimes language teachers overemphasize this reciprocal relationship between literature and culture to the extent that learners' own cultures are marginalized and sometimes even neglected. As Lazar (1993) warns us, "being made to read texts so alien to their own experience and background may only increase students' sense of frustration, inferiority, and even powerlessness (p. 3).

One way to prevent from culture imperialism within literature-based EFL/ESL classrooms is to look for "quality multicultural literature reflecting many cultures" (Vardell, et al., 2006, p. 736). Further, rather than trying to demonstrate the superiority of one culture over another, teachers are recommended to take an unbiased position towards cultures, just focusing on the differences that exist between them. Similarly, learners should be exposed to a genuine depiction of the L2 culture through literary texts rather than an idealized version of it and be encouraged to be tolerant of diversity among cultures.

\section{Conclusion}

There exists an ever-growing recognition that the integration of literature and literary texts (especially novels and short stories) into language classrooms would provide EFL/ESL learners with opportunities to develop all aspects of their English language proficiency. However, the recognition of the value of literature for language classrooms does not mean that teachers concede as to how they should employ literature in their classrooms. In fact, this is exactly the point where controversies arise. The recommendations given in this paper for the integration of literature into language classroom can serve as guidelines that teachers may follow based upon their particular classroom needs to enhance the efficacy of their literary texts for the development of learners' communicative skills in the L2.

\section{References}

Alptekin, C. (2006). Cultural familiarity in inferential and literal comprehension in L2 reading. System, 34, 494-508. doi:10.1016/j.system.2006.05.003, http://dx.doi.org/10.1016/j.system.2006.05.003

Bugel, K., \& Buunk, B. (1996). Sex differences in foreign language text comprehension: The role of interests and prior knowledge. Modern Language Journal, 80, 15-31. doi:10.2307/329055, http://dx.doi.org/10.2307/329055

Carter, R. (2007). Literature and language teaching1986-2006: A review. International Journal of Applied Linguistics, $\quad 17, \quad 3-13 . \quad$ doi:10.1111/j.1473-4192.2007.00130.x, http://dx.doi.org/10.1111/j.1473-4192.2007.00130.x

Chan, P. K. W. (1999). Literature, language awareness and EFL. Language Awareness, 8, 38-50. doi:10.1080/09658419908667116, http://dx.doi.org/10.1080/09658419908667116 
Doiron, H. L. (2009). Bridging Gatsby into the EFL/ESL classroom. The Internet TESL Journal, XV. [Online] Available: http://iteslj.org/

Edmondson, W. (1997). The role of literature in foreign language teaching and learning: Some valid assumptions and invalid arguments. AILA Review, 12, 42-45.

Floris, F. D. (2004). The power of literature in EFL classrooms. K@ta, 6, 1-12.

Frantzen, D. (2002). Rethinking foreign language literature: Towards an integration of literature and language at all levels. In V. M. Scott \& H. Tucker (Eds.), SLA and the literature classroom: Fostering dialogues (pp. 109-130). Boston: Heinle \& Heinle.

Gajdusek, L. (1988). Toward wider use of literature in ESL: Why and how. TESOL Quarterly, 22, 227-257. doi:10.2307/3586935, http://dx.doi.org/10.2307/3586935

Ghosn, I. K. (2002). Four good reasons to use literature in primary school ELT. ELT Journal, 56, 172-179. doi:10.1093/elt/56.2.172, http://dx.doi.org/10.1093/elt/56.2.172

Hinkel, E. (2006). Current perspectives on teaching the four skills. TESOL Quarterly, 40, 109-131. doi:10.2307/40264513, http://dx.doi.org/10.2307/40264513

Hişmanoğlu, M. (2005) Teaching English through literature. Journal of Language and Linguistic Studies, 1, 53-66.

Howatt, A. P. R. (1984). A history of English language teaching. Oxford: Oxford University Press.

Khatib, M., Derakhshan, A., \& Rezaei, S. (2011). Why and why not literature: A task-based approach to teaching literature. International Journal of English Linguistics, 1, 213-218.

Krashen, S. (1998). Bridging inequity with boos. Educational Leadership, 55, 18-22.

Lazar, G. (1993). Literature and language teaching. London: Cambridge University Press.

MacKenzie, I. (2000). Institutionalized utterances, literature, and language teaching. Language and Literature, 9, 61-78. doi:10.1177/096394700000900105, http://dx.doi.org/10.1177/096394700000900105

Maley, A. (1989). Down from the pedestal: Literature as resource. In C. J. Brumfit \& R. A. Carter (Eds.), Literature and the learner: Methodological Approaches (pp. 10-23). London: McMillan.

McGinley, W., Kamberelis, G., Mahoney, T., Madigan, D., Rybicki, V., \& Oliver, J. (1997). Revisiting reading and teaching literature through the lens of narrative theory. In T. Rogers \& A. O. Soter (Eds.), Reading across cultures: Teaching literature in a diverse society (pp. 42-68). New York: Teachers College Press.

McKay, S. (1982). Literature in the ESL classroom. TESOL Quarterly, 16, 529-536. doi:10.2307/3586470, http://dx.doi.org/10.2307/3586470

McKay, S. (2001). Literature as content for ESL/EFL. In M. Celce-Murcia (Ed.), Teaching English as a second or foreign language (3rd ed., pp. 319-332). Boston: Heinle \& Heinle.

Murray, D. E., \& McPherson, P. (2006). Scaffolding instruction for reading the Web. Language Teaching Research, 10, 131-156. doi:10.1191/13621688061r189oa, http://dx.doi.org/10.1191/13621688061r189oa

Nassaji, H. (2002). Schema theory and knowledge-based processes in second language reading comprehension: A need for alternative perspectives. Language Learning, 52, 439-481. doi:10.1111/0023-8333.00189, http://dx.doi.org/10.1111/0023-8333.00189

Neuman, S. B., \& Celano, D. (2001). Access to print in low-income and middle-income communities: An ecological study of four neighborhoods. Reading Research Quarterly, 36, 8-26. doi:10.1598/RRQ.36.1.1, http://dx.doi.org/10.1598/RRQ.36.1.1

Preston, W. (1982). Poetry ideas in teaching literature and writing to foreign students. TESOL Quarterly, 16, 489-502. doi:10.2307/3586467, http://dx.doi.org/10.2307/3586467

Steffensen, M. S., Joag-Dev, C., \& Anderson, R. C. (1979). A cross-cultural perspective on reading comprehension. Reading Research Quarterly, 15, 10-29. doi:10.2307/747429, http://dx.doi.org/10.2307/747429

Tayebipour, F. (2009). In defence of teaching literature to EFL students in the era of globalization. In L. J. Zhang, R. Rubdy, \& Alsagoff (Ed.), Englishs and literatures-in-English in a globalized world: Proceedings of the $13^{\text {th }}$ international conference on English in Southeast Asia (pp. 213-219). Singapore: National Institute of Education, Nanyang Technological University

Vardell, S. M., Hadaway, N. L., \& Young, T. A. (2006). Matching books and readers: Selecting literature for English learners. The Reading Teacher, 59, 734-741. doi:10.1598/RT.59.8.1, http://dx.doi.org/10.1598/RT.59.8.1 